\title{
Case study: reflections of a critical care nurse
} on futile treatment

Wai Fan Vivien Keung RN; BN, Staff Nurse, North District Hospital, Hong Kong

Sek Ying Chair RN; MBA, PhD, Assistant Professor, The Nethersole School of Nursing, The Chinese University of Hong Kong, Hong Kong

E-mail: sychair@cuhk.edu.hk

Key Words: code of ethics $\quad$ ethical decision-making $*$ futility $*$ nursing $\quad$ treatment withdrawal

\section{SUMMARY}

- End-of-life decision making a common ethical problem in clinical practice within critical care settings. However, in our experience, decision making is dominated by physicians with low participation of nurses, the patient and family members.

- This article presents a case study in which professional conflict arose about the appropriateness of medical treatment, when a patient was not expected to survive.

- Treatment is defined as futile when it does not accomplish its intended goal, that is, to provide a beneficial physiological effect.

- Nurses should uphold the Code of Ethics and maintain the moral integrity. As patients' advocates, nurses should enhance the collaborative relationships with other health care professionals in order to reach moral consensus in the interest of good patient care.

- In the setting of end-of-life care, up to date knowledge - especially in the area of ethics - and competent communication skills are essential to provide high quality care.

\section{INTRODUCTION}

Nursing is a vital component of the health care system in every part of the world, because nurses not only have an intimate contact with clients but they also have a close working relationship with other healthcare professionals. Melia (2001) pointed out that dealing with moral and ethical decisions, particularly in the intensive care unit (ICU), is a frequent event. It is an area in which nursing and medical perspectives are often at odds and under these circumstances nurses may use ethical analysis in order to help them make sound judgements. For professional nurses, codes of ethics provide fundamental guidelines for nurses when making ethical decisions in patient care.

Ethical decisions are frequently faced by nurses, and end-of-life decisionmaking has been identified as the most frequent ethical problem in clinical practice (Oberle \& Hughes, 2001). Such decisions may include whether or not to have a do-not-resuscitate (DNR) order and when to withdraw lifesustaining therapies such as antibiotic therapy, dialysis, administration of fluids and nutrition, or mechanical ventilation (Thelen, 2005).

Bosshard et al. (2005) showed that there was a low level of patient involvement in end-of-life decisions. Many critically ill patients are unable to participate in medical decision-making because of their severity of illnesses; they may be physically or mentally unable to participate. Baggs and Schmitt (2000) found that physicians often make end-of-life decisions alone or with minimal input from others. When patients' family members are involved, physicians are most commonly the initiators of discussions about end-of-life treatment and often dominate the discussions (Curtis et al., 2002).

\section{CASE SCENARIO}

In this reflection, a clinical situation in an ICU will be described and the concept of futility will be illustrated. The Code of Ethics for nurses in Hong Kong (Nursing Council of Hong Kong, 2002) will then be discussed. Finally, nursing implications and conclusions will be drawn.

A 61-year-old woman was admitted to ICU due to multi-organ dysfunction syndrome as a result of sepsis. Despite the broad-spectrum antibiotic therapy, high dose inotropic support, invasive positive pressure ventilation and fluid resuscitation, continuous veno-venous hemofiltration (CVVH) had to be initiated due to renal failure.

CVVH circulates blood through a haemofilter and yields an ultrafiltrate solution with the composition of plasma water containing low molecular weight non-protein bound solutes. It is a type of dialysis that removes fluids and solutes slowly, correcting the electrolyte and metabolic abnormalities (Paton, 2003). Pre-filter fluid replacement and minimal heparin were used during the process of $\mathrm{CVVH}$ as a preventative measure to prevent clotting of blood in the extracorporeal circuit; however, early clotting of the extracorporeal circuit still occurred. Meanwhile, the platelet count of this patient gradually decreased, and the decrease in platelet count was believed to be due to heparin-induced thrombocytopenia.

Due to the patient's deteriorating situation with respect to $\mathrm{CVVH}$, (WFVK) discussed with the physician the possibility of using heparin-free haemofiltration by using regional citrate and calcium infusion to prevent clotting of the extracorporeal circuit. The doctor expressed his concerns about using a regional anticoagulant. One of his concerns was about the values and the attitude of some nursing staff towards caring for a patient with CVVH. Specifically, that some nurses felt that they had insufficient experience in the care of patients undergoing dialysis and therefore did not consider that clotting of the circuit was within their domain of responsibility. Furthermore, they considered citrate anticoagulation to be too laborious and cumbersome. It requires constant adjustments of the citrate infusion rate to blood-flow rate or ionized calcium level in the extracorporeal circuit (Apsner et al., 2005). It is also important for nurses to closely monitor the patient for possible complications such as metabolic alkalosis when using citrate anticoagulation, as citrate metabolism generates bicarbonate (De Vos \& Hombrouckx, 2003). Previously, some nursing staff had also challenged the appropriateness of treating septic patients with $\mathrm{CVVH}$ with regard to its cost-effectiveness (in relation to mortality outcome) during a time of financial deficits within Hong Kong health care system.

As a consequence of the above issues no further CVVH intervention occurred, the patient's thrombocytopenia became worse and her condition deteriorated further, at which point $\mathrm{CVVH}$ was seen as a futile treatment. CVVH was withdrawn and the patient died soon after. 


\section{ETHICAL PROBLEMS ARISING FROM THE CASE}

In Hong Kong, health care services are subsidised by the Hong Kong Government. Despite the economic downturn since 1997, the majority $(95 \%)$ of public sector funding is derived from government general tax revenue with the remaining $5 \%$ recovered from fees and charges at the point-of-care (Leung et al., 2005). Therefore, at the time of writing, financial deficits in the government, cost and resources retention was the main concern for every hospital. Implementation of any kind of continuous renal replacement therapy to a critically ill client has been criticised due to its expensive cost (Cerda et al., 2002), although the cost of CVVH treatment is not made public by the government.

The benefit of treatment with CVVH is not in doubt, as it effectively balances fluid and electrolytes as well as removing metabolic wastes. In this case, use of the CVVH treatment and the early clotting of circuit would definitely have increased the medical costs, but whether or not the treatment should be provided to the patient requires discussion, as some nurses argued that CVVH was a futile treatment for sepsis patients whose primary medical diagnosis was not renal failure.

Once a healthcare professional agrees to admit a patient, he or she acquires the responsibility for that patient (Thompson et al., 2000). Furthermore, patients should have the right to hear the truth, understanding the benefits and burdens of the intervention, and to be treated competently (Pitorak, 2003). Patients are usually assumed to have rights to a certain level of health care, such as the right to be respected, make informed choices and have pain managed effectively (Murray, 2003). In this case, some medical personnel believed that using CVVH to treat a sepsis patient was futile because the patient's medical problem was not primarily renal failure. In this context therefore, it is argued that the understanding of futile treatment should be evaluated before making a decision to withdraw treatment, and only then (if it is agreed that the treatment is beneficial) should the nursing role in preventing frequent clotting of extracorporeal circuit be discussed.

\section{CONCEPT OF FUTILITY}

It is common that critical care nurses question the correctness of medication dosage and the appropriateness of certain medical treatments. During the time of financial difficulty in the Hong Kong health care industry, the concept of futility has emerged. Futile means: useless, unusual, hopeless, inappropriate, non-beneficial, unreasonable, or extraordinary (Lesage et al., 2001). It is also further defined in the dictionary (Oxford Advanced Learner's English-Chinese Dictionary, 1999) as being pointless and producing no result.

Treatment is referred to as futile if it does not conform to the patient's goals, to legitimate goals of medical practice, or to accepted community standards. Treatment may also be futile if it is ineffective most of the time (Angelucci, 2006). A treatment is probably not futile if there is a real opportunity to achieve some desirable results including success, benefits (Lesage et al., 2001) or able to improve and restore a quality of life that would be satisfactory to the patient (Darr, 2000).

In this reflection, CVVH was claimed by some healthcare workers to be a futile treatment because the patient's condition had not improved but deteriorated with the development of heparin-induced thrombocytopenia and frequent clotting of the circuit induced deterioration of her anaemic state.

When analysing this case, it is suggested that CVVH should not be considered to be a futile treatment. According to the Surviving Sepsis Campaign (2004), CVVH is a recommended treatment in severe sepsis for better fluid control, acid-base and electrolyte balance in multi-organ failure patients or haemodynamically unstable septic patients. It creates a more normal, slow and gradual clearance of waste products. This gradual fluid and electrolyte removal results in less haemodynamic instability (Jones, 2004). Furthermore, the elimination of septic mediators and the lowering of intracranial pressure are additional advantages to the use of CVVH (Manns et al., 1998). CVVH has been shown to be effective and it is a widely used treatment modality in critical care settings (Briglia, 2005).
Although heparin-induced thrombocytopenia could be a problem for patients receiving CVVH, many studies (Apsner, 2001; Tolwani et al., 2001; Bauer, 2005) also indicate that heparin-induced thrombocytopenia can be managed by replacing heparin with citrate, as citrate is an effective anticoagulant in CVVH therapy. Citrate anticoagulation can eliminate heparin-associated adverse effects and increase biocompatibility of the dialysis procedure (Apsner, 2001). In addition, regional citrate anticoagulation is associated with prolonged filter survival and increased completion of scheduled filter life span, when compared to heparin anticoagulation (Bagshaw et al., 2005).

There is a possibility that had citrate been considered for this patient, heparin-induced thrombocytopenia could have been avoided. This may have resulted in a better treatment outcome. The predicted mortality of this patient was already high due to her sepsis, and it cannot be concluded that her death was due solely to the withdrawal of CVVH. But, this raises the issue of patient advocacy and, as the patient's advocate the nurse should always seek ways and methods to achieve appropriate treatment goals and improve well-being of the patient.

\section{THE CODE OF ETHICS FOR NURSES IN HONG KONG}

To act ethically on behalf of patients is integral to the nursing profession. In Hong Kong, the Code of Ethics for Nurses (Nursing Council of Hong Kong, 2002) delineates moral principles and provides nurses with a basis for ethical practice. It also indicates to the community the values that nurses should hold. Nurses in all specialties are required to acknowledge the code and incorporate it into their clinical practice.

The fundamental responsibilities of nurses are to promote health, prevent illness, restore health, and alleviate suffering caused by ill health (Sole et al., 2005). There are four main value statements that indicate the ethical responsibilities of nurses including: to respect life, to improve quality of life and respect individual rights and dignity, to be responsive to society's needs and work towards a healthy community through partnership, and to strive for excellence and assure quality of care (Nursing Council of Hong Kong, 2002).

By application of the above value statements, nurses can improve their personal qualities, provide quality nursing care and earn the trust of those within their care. Moreover, nurses should maintain a high standard of care and enhance patients' well-being. Nurses should also collaborate with others in initiating and supporting actions that work towards the goal of 'health for all'.

As in this case, some nursing staff labelled CVVH as a futile treatment to the patient and may have been using this as an excuse to avoid taking care of this particular patient. Refusal to care for a critically ill patient cannot justified on the grounds of patients' and nurses' best interests because of the nurses own (perceived) capabilities. Once a patient has been admitted to ICU, nurses are responsible for providing safe and competent care for that patient, with the aim of promoting well-being and saving life, to the best of their ability.

Safe and competent practice can be maintained and developed through continuous education and nurses should not excuse themselves from practice due to a lack of knowledge or experience. However, it is important that nurses do not take on patient care roles unless they are either competent to do so, or can be supervised by a clinical colleague with relevant expertise. Critical care is an area where specialist knowledge and skills are essential to providing high quality care (Smith, 2004). Nowadays, increased specialisation of health care services means that nurses require in-depth knowledge of the speciality in which they work; and they must adapt quickly to new knowledge and skills demands (Tennant \& Field, 2004).

\section{PERSONAL REFLECTION}

Nurses in ICU spend most of their time in direct patient care, which includes preparation and management of dialysis (Harrison \& Nixon, 2002). Sepsis-induced multiple-organ failure, which occurs frequently in ICU patients, is often fatal (Hansard et al., 2004). Continuous renal replacement therapy (CRRT) is now one of the core treatments provided 
within a modern critical care unit. Although it has been argued that nurses should not refuse to care for patients undergoing CRRT, it is acknowledged that novice nurses will be limited in their ability to do so, and that expert peer supervision and continuing education are important factors to help develop their competence.

A lack of factual knowledge may limit a nurse's ability to make a sound ethical judgement (Shotton, 2000). Nurses should undertake continuous education in order to advance their standards and knowledge in theory as well as in practice. Both the hospital and the individual should value learning opportunities in providing high standard of care to clients. Other than regular in-services provided by the Nurse Specialist of the case study ICU, short renal courses offered by various local nursing professional organisations are available every year.

Even when things cannot be done perfectly a nurse should do her best (Husted \& Husted, 2001) and although nurses cannot initiate most intensive care interventions, they do play a crucial role in influencing the treatment plan for the benefit of the patient (Shotton, 2000). In their role as patient advocate nurses are responsible for suggesting and discussing the use of appropriate treatments with their physician colleagues. Nurses and physicians have a common goal to achieve the best possible health care for the patient, and to appreciate each other's points of view (Jormsri, 2004). Both nursing and medical professions would benefit from sharing concerns and supporting each other, not only informally in the day-to-day work, but also formally during institutional as well as patient treatment planning (Greenfield, 1999).

In Hong Kong, inter-professional relationships can sometimes be challenging, but the development of collaborative relationships with physicians is important, and it can have a liberating effect for nurses with regard to moral decisions and actions.

If the patient treatment plan in this case study had been approached collaboratively, the CVVH treatment goal would have been determined between both medical and nursing staff, and it is possible that a different conclusion may have been reached. Had this been the case, then the outcome of the patient in this case might have been better.

Nurses, including those in Hong Kong, often complain of powerlessness over decision-making due to their position in the hierarchy of health care system (Erlen \& Frost, 1991; Lam, 2001). However, nurses often forget their crucial role in bringing the inter-professional team together, therefore, nurses should be encouraged to participate in policy making in fostering ethical decisions.

Lipp (1998) found that the hospital and nurses' colleagues influenced ethical decision-making, thus causing a profound effect on the outcome of patients and Peter et al. (2004) showed that moral integrity of junior nurses was passive when confronted with the values of their senior nursing co-workers.

May (1996) stated there are three aspects to moral integrity: critical thinking, coherence of value orientation, and the commitment to act in a principled way. Moral integrity, either as a person or as a professional, refers to the wholeness in the relationship between the actions, and the values and beliefs (Hardingham, 2004). Therefore, it is important for nurses to assess their own beliefs and knowledge (Cogliano, 1999). The development of personal values and professional values are important, and ethics education that enables nurses to become empowered, confident in decision-making and reflective about their actions, should be provided for all levels of health care professions.

Many ICUs face dilemmas between limited budgets, increased healthcare costs and demand. The views of constraints on the patient-carer relationships are sometimes captured by the external factors including economic and inadequate nurse to patient staffing ratios (Brett, 2002). Ideally, nursing administrators should ensure that adequate resources are available to facilitate ethical practice.

Nurses should be aware of their important role in affecting patient treatment plans, especially in the context of discussions about futile care, and should negotiate on the patient's behalf to prevent or resolve moral conflict (Taylor, 1995). Furthermore, nurses should not define futility according to their personal bias, nor should it be defined according to their ability to provide the required care. In order to provide competent and ethical care, nurses need to maintain their knowledge and skills at a level that benefits rather than harms their patients.

Ferrand et al. (2003) reported that the majority of nursing staff and physicians thought that ethical decision-making should be collaborative, however, some nurses believed that they were not involved in making decisions. Without including nursing staff in a patient treatment plan, nurses' support for a decision cannot be ensured. In this case study, even though there is no legal requirement for nurses to agree with a decision for withdrawal of treatment, they are clearly responsible and accountable at law for their own actions.

Intensive care should be a team effort and there seems to be a strong desire within the ICU team that moral consensus should be achieved in the interests of good patient care (Melia, 2001). The concept of futility was raised in this case study, within the constraints of financial burden, making it difficult for nurses to make an objective judgment - based in the patient's best interests - about futile treatment. On the other hand, nurses should be advocates and should collaborate with other health care professionals to provide care according in the best interest of individual patients. Professional nurses should be accountable for what they say and do and it is important for nurses to uphold and adhere to their professional Code of Ethics. Ethical reflection and analysis may not always resolve a disagreement but inter-professional debate is nevertheless valuable.

Being competent and confident requires effort by individual nurses to enhance their knowledge about new treatments and technology. Twenty years ago, CVVH was a new treatment for acute renal failure; it is now widely used for many other patients. The nurses in this case study, who claimed that they were not competent to manage a patient with $\mathrm{CVVH}$, should consider ways to develop their knowledge in this area. Institutions also have a responsibility to provide adequate training and education opportunities for nurses to ensure their professional development and clinical competence.

\section{CONCLUSIONS}

Treatment is defined as futile when it does not accomplish its intended goal, that is, a beneficial physiological effect (Miller et al., 2006). Futility should be given careful consideration because once a treatment has been judged to be futile a patient may lose the opportunity to receive such a treatment. Nurses should be as objective as possible and be aware of their own power in influencing the outcomes of medical treatment. Furthermore, nurses have a professional responsibility (as the patient's advocate) to participate in the ethical decision-making process.

\section{REFERENCES}

Angelucci PA. (2006) Ethics in practice. Grasping the concept of medical futility. Nursing Management 37 (2), 12-14.

Apsner R. (2001). Simplified citrate anticoagulation for high-flux hemodialysis. American Journal of Kidney Disease 38 (5), 979-987.

Apsner R, Buchmayer H, Gruber D, Sunder-Plassmann G. (2005) Citrate for long-term hemodialysis: prospective study of 1009 consecutive high-flux treatments in 59 patients. American Journal of Kidney Diseases 45 (3), 557-564.

Baggs JG, Schmitt MH. (2000) End-of-life decisions in adult intensive care: current research base and directions for the future. Nursing Outlook 48 (4), 158-164.

Bagshaw SM, Laupland KB, Boiteau PJE, Godinez-Luna T. (2005) Is regional citrate superior to systemic heparin anticoagulation for continuous renal replacement therapy? A prospective observational study in an adult regional critical care system. Journal of Critical Care 20 (2), 155-161.

Bauer E. (2005) Citrate kinetics in patients receiving long-term hemodialysis therapy. American Journal of Kidney Disease 46 (5), 903-907.

Bosshard G, Nilstun T, Bilsen J, Norup M, Miccinesi G, van Delden JJ, Faisst K, van der Heide A, European End-of-Life Consortium. 
(2005) Forgoing treatment at the end of life in 6 European countries. Archives of Internal Medicine 165 (4), 401-407.

Brett A. (2002) Problems in caring for critically and terminally ill patients: perspectives of physicians and nurses. HCE Forum 14 (2), 132-147.

Briglia AE. (2005) The Current State of Nonuremic Applications for Extracorporeal Blood Purification. Seminars in Dialysis 18 (5), 380390.

Cerda J, Prendergast J, Kilcullen P. (2002) Challenges in acute and chronic renal failure: Acute renal failure in the ICU treated with CRRT: Prospective evaluation of severity of disease, patient's outcomes and costs. Nephrology Dialysis Transplantation. XLII Congress of the ERA-EDTA 20 (5), 191-192.

Cogliano JF. (1999) The Medical Futility Controversy: Bioethical Implications for the Critical Care Nurses. Critical Care Nurses Quarterly 22 (3), 81-88.

Curtis JR, Engelberg RA, Wenrich MD, Nielsen EL, Shannon SE, Treece PD, Tonelli MR, Patrick DL, Robins LS, McGrath BB, Rubenfeld GD. (2002) Studying communication about end-of-life care during the ICU family conference: development of a framework. Journal of Critical Care 17 (3), 147-160.

Darr K. (2000) Nexus: ethics, law, and management. Futile treatment and the health services manager. Hospital Topics 78 (3), 27-30.

De Vos J, Hombrouckx R. (2003) Citrate anticoagulation and adverse events. EDTNA ERCA Journal 29 (3), 112-113.

Erlen JA, Frost B. (1991) Nurses' perceptions of powerlessness in influencing ethical decisions. Western Journal of Nursing Research 13 (3), 397-407.

Ferrand E, Lemaire F, Regnier B, Kuteifan K, Badet M, Asfar P, Jaber S, Chagnon JL, Renault A, Robert R, Pochard F, Herve C, Brun-Buisson C, Duvaldestin P; French RESSENTI Group. (2003) Discrepancies between perceptions by physicians and nursing staff of intensive care unit end-of-life decisions. American Journal of Respiratory and Critical Care Medicine 167 (10), 1310-1315.

Greenfield LJ. (1999) Doctors and nurses: a troubled partnership. Annals of Surgery 230 (3), 279-288.

Hansard PC, Haseeb MA, Maning RA, Salwen MJ. (2004) Recovery of bacteria by continuous renal replacement therapy in septic shock and by ultrafiltration from an in vitro model of bacteremia. Critical Care Medicine 32 (4), 932-937.

Hardingham LB. (2004) Integrity and moral residue: nurses as participants in a moral community. Nursing Philosophy 5 (2), 127-134.

Harrison L, Nixon G. (2002) Nursing activity in general intensive care. Journal of Clinical Nursing 11 (2), 158-167.

Husted GL, Husted JH. (2001) Ethical Decision Making in Nursing and Healthcare. ( $3^{\text {rd }}$ ed.). New York: Springer Publising Company.

Jones S. (2004) Heat loss and continuous renal replacement therapy. American Association of Critical-Care Nurses 15 (2), 223-230.

Jormsri P. (2004) Moral conflict and collaborative mode as moral conflict resolution in health care. Nursing and Health Sciences 6, 217-221.

Lam Z. (2001). Collaboration among health care professionals in primary health care. Hong Kong Nursing Journal 37 (2), 15-19.

Lesage P, Russell K, Portenoy MD. (2001) Ethical Challenges in the Care of Patients with Serious illness. Pain Medicine 2 (2), 121-130. Leung GM, Wong IOL, Chan W, Choi S, Lo S. (2005) The ecology of health care in Hong Kong. Social Science \& Medicine 61 (3), 577590.

Lipp A. (1998) An enquiry into a combined approach for nursing ethics. Nursing Ethics 5 (2), 123-137.

May L. (1996) The Socially Responsive Self: Social Theory and Professional Ethics. Chicago : The University of Chicago Press.

Manns M, Sigler MH, Teehan BP. (1998) Continuous renal replacement therapies: An update. American Journal of Kidney Disease 32 (2), 185-207.

Melia KM. (2001) Ethical issues and the importance of consensus for the intensive care team. Social Science \& Medicine 53 (6), 707-719.

Miller C, Funk M, Wiegand D. (2006) Judgments of nurses and physicians regarding futility and withdrawal of treatment in medical and surgical intensive care units (ICUs). American Journal of Critical Care 15 (3), 326-327.

Murray EJ. (2003) Struggling for dignity and respect: patients' beliefs of their rights while hospitalized in an acute care facility. Unpublished master's thesis, University of Miami.

Nursing Council of Hong Kong. (2002) Code of professional conduct and code of ethics for nurses in Hong Kong. Nursing Council, Hong Kong.

Oberle K, Hughes D. (2001) Doctors' and nurses' perceptions of ethical problems in end-of life decisions. Journal of Advanced Nursing 33 (6), 707-715.

Oxford Advanced Learner's English-Chinese Dictionary (4th ed.). (1999). Hong Kong, Oxford University Press.

Paton M. (2003) Continuous renal replacement therapy: slow but steady. Nursing 33 (6), 48-50.

Peter E, Lunardi VL, Macfarlane A. (2004) Nursing resistance as ethical action: literature review. Journal of Advanced Nursing 46 (4), 403416.

Pitorak EF. (2003) Respecting the dying patient's rights. Home Healthcare Nurse 21 (12), 833-836.

Shotton L. (2000) Can nurses contribute to better end-of-life care? Nursing Ethics 7 (2), 134-140.

Smith C. (2004) Time for change - time to engage. Nursing in Critical Care 9 (4), 149-50.

Sole ML, Klein DG, Moseley MJ. (2005) Introduction to critical care nursing. St. Louis: Elsevier Saunders.

Surviving Sepsis Campaign. (2004) Guidelines for the management of severe sepsis and septic shock: background, recommendations, and discussion from an evidence-based review. Critical Care Medicine 32 (11), 446-597.

Taylor C. (1995) Medical Futility and Nursing. Journal of Nursing Scholarship 27 (4), 301-306.

Tennant S, Field R. (2004) Continuing professional development: does it make a difference? Nursing in Critical Care 9 (4), 167-172.

Thelen M. (2005) End-of-life decision making in intensive care. Critical Care Nurse 25 (6), 28-38.

Thompson IE, Melia KM, Boyd KM. (2000) Nursing Ethics. London: Churchill Livingstone.

Tolwani AJ, Campbell RC, Schenk MB, Allon M, Warnock DG. (2001) Simplified citrate anticoagulation for continuous renal replacement therapy. Kidney International 60 (1), 370-374. 